\title{
A Case Report on Deliberate Self-poisoning with Imidacloprid in a Young Female - Overview of a Newer Insecticide Poisoning
}

Sabin Thapaliya', Bhupendra K Basnet ${ }^{2}$, Santa K Das³, Rakshya Thapa ${ }^{4}$

\author{
Author(s) affiliation \\ 'Department of Internal Medicine, \\ Tribhuvan University Teaching \\ Hospital, Institute of Medicine, \\ Maharajgunj, Kathmandu, Nepal \\ ${ }^{2}$ National Academy of Medical \\ Sciences, Bir Hospital, Mahaboudha, \\ Kathmandu, Nepal \\ ${ }^{3}$ Department of Pulmonology and \\ Critical Care Medicine, Maharajgunj \\ Medical Campus, Tribhuvan \\ University Teaching Hospital, \\ Institute of Medicine, Maharajgunj, \\ Kathmandu, Nepal \\ ${ }^{4}$ Helping Hands Community \\ Hospital, Chabahil, Kathmandu, \\ Nepal
}

\section{Corresponding author}

Sabin Thapaliya, MBBS, MD sabinthapaliya@gmail.com

\section{Submitted}

Feb 16, 2021

\section{Accepted}

Mar 29, 2021

\begin{abstract}
Imidacloprid is a newer insecticide of the group Neonicotinoids. It is safer to humans and hence considered a better alternative to organophosphorus compounds, especially in areas like Nepal with higher incidence of deliberate self-poisoning. There has been an increase in the number of reported cases of imidacloprid poisoning from South-East Asian countries, but none from Nepal. We report a case admitted in Intensive Care Unit with neurological manifestations, respiratory failure and development of Acute Kidney Injury following acute imidacloprid poisoning.
\end{abstract}

\section{Keywords}

Acute kidney injury, imidacloprid poisoning, neurological manifestation, respiratory failure

\section{INTRODUCTION}

$\mathrm{D}$ eliberate self-harm with ingestion of organophosphorus compounds is a common health problem in Nepal. With increasing use of newer insecticides, there is an increase in the number of reported cases of poisoning with newer compounds, like Imidacloprid, from all over the world. The clinical consequences and management plans for these newer insecticides are not well described. Prior case reports of Imidacloprid poisoning have shown mild symptoms and signs such as nausea, vomiting, tachycardia to severe respiratory failure, central nervous system (CNS) depression, seizures and even death in humans. ${ }^{1}$ This patient of Imidacloprid poisoning presented with severe features but recovered with supportive treatment.

\section{CASE PRESENTATION}

A 26 years old female was brought to emergency department of Helping Hands Community Hospital with unresponsiveness and increased salivation for 3 hours after ingestion of an unknown insecticide. She had no history of vomiting following ingestion of insecticide. At presentation her pulse was 60 beats/min, BP 100/60 mmHg, axillary temperature $98^{\circ} \mathrm{F}$, respiratory rate $20 / \mathrm{min}, \mathrm{SpO}_{2} 98 \%$ in room air and pupils were 


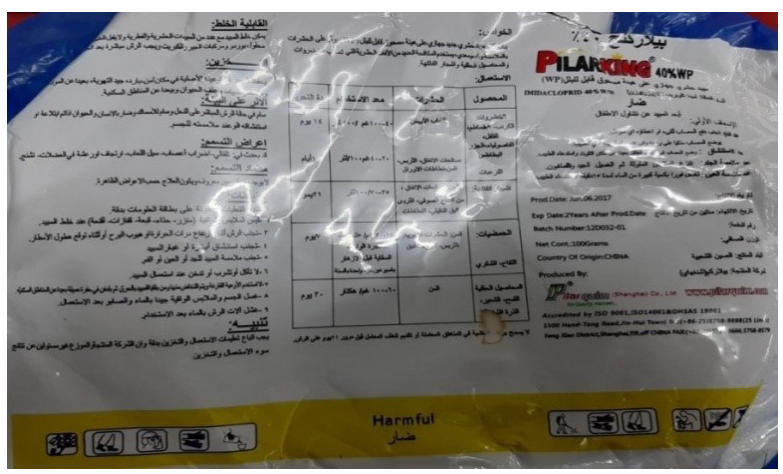

Fig 1. The packaging of Imidacloprid (Brand name: Pilarking) $40 \% \mathrm{w} / \mathrm{w}$ recovered from the patient

dilated but reactive to light bilaterally. Her Glasgow Coma Scale (GCS) was E1V1M5. Initially, with the suspicion of organophosphorus poisoning, she was treated with atropine and gastric lavage. Later the cover of the poison was recovered (Figure 1) and her management plan changed.

Although initially planned, the patient was not given Pralidoxime due to its lack of benefit shown in case studies. Further atropine was not given. The initial laboratory investigations showed neutrophilic leucocytosis with WBC 28830/cumm (90\% neutrophils), hemoglobin $12.8 \mathrm{~g} / \mathrm{dL}$, platelets 346000/cumm, random blood sugar (RBS) $205 \mathrm{mg} /$ $\mathrm{dl}$, urea $20.5 \mathrm{mg} / \mathrm{dL}$, creatinine $0.7 \mathrm{mg} / \mathrm{dL}, \mathrm{Na}-141$ $\mathrm{mEq} / \mathrm{L}, \mathrm{K}-3.5 \mathrm{mEq} / \mathrm{L}$ and prothrombin time (PT) 15.1s (control 12s). Serum cholinesterase level was $5043 \mathrm{U} / \mathrm{L}$ (normal range 3930-10800 U/L). Urine for pregnancy test was negative and Urine routine examination showed pus cells 10-12/HPF (high power field), red blood cells (RBC) 0-2/HPF. Repeat fasting blood sugar was normal.

She was started empirically on IV Tazobactam/ Piperacillin and with other supportive therapy like Ondansetron pro re nata (PRN), IV fluids and proton pump inhibitor (PPI); and was admitted to intensive care unit (ICU) due to low GCS. Ten hours after admission (about 13 hours after ingestion of Imidacloprid), her peripheral arterial oxygen saturation $\left(\mathrm{SpO}_{2}\right)$ measured by pulse oximetry started decreasing and she needed oxygen supplementation at $>6 \mathrm{~L} / \mathrm{min}$. With her low GCS, falling $\mathrm{SpO}_{2}$ and increasing risk of aspiration, she was intubated and was kept under ventilator support. Fraction of inspired oxygen $\left(\mathrm{FiO}_{2}\right)$ was gradually decreased on the same day.

With supportive treatment alone, her GCS gradually improved over the next 24 hours to E4M6. Her ventilator support was gradually changed to spontaneous mode with $\mathrm{FiO}_{2}$ 35\% and the patient was successfully extubated after 72 hours of intubation. During this period she was given $1.2 \mathrm{mg}$ of atropine due to bradycardia (Heart Rate < 40bpm).

She developed acute kidney injury (AKI) after 36 hours of admission. Although her urine output was adequate, her serum creatinine was $2.3 \mathrm{mg} /$ $\mathrm{dl}$ after $36 \mathrm{~h}$ (serum urea $40.2 \mathrm{mg} / \mathrm{dl}$ ), $3.2 \mathrm{mg} / \mathrm{dl}$ after $60 \mathrm{~h}$ (serum urea $58 \mathrm{mg} / \mathrm{dl}$ ). Her $\mathrm{Hb}$ decreased from $12.8 \mathrm{~g} / \mathrm{dL}$ at admission to $9.9 \mathrm{~g} / \mathrm{dL}$ at $36 \mathrm{~h}$ to $8.7 \mathrm{~g} / \mathrm{dL}$ at $60 \mathrm{~h}$. Her liver function tests at $60 \mathrm{~h}$ was Total bilirubin $1.5 \mathrm{mg} / \mathrm{dL}$, direct bilirubin $0.5 \mathrm{mg} /$ $\mathrm{dL}$, Alanine aminotransferase - $141 \mathrm{U} / \mathrm{L}$, aspartate aminotransferase $731 \mathrm{U} / \mathrm{L}$, alkaline phosphatase $33 \mathrm{U} / \mathrm{L}$. Neurology consultation was done $12 \mathrm{~h}$ after admission for low GCS and non-contrast computed tomography (NCCT) of the head was done which showed normal findings. Nephrology consultation was done for her worsening $A K I$ and she was given sodium bicarbonate for her metabolic acidosis $(\mathrm{pH}-$ 7.1, $\left.\mathrm{PCO}_{2}-29.4, \mathrm{HCO}_{3}-14\right)$, initially injectable then oral sodium bicarbonate.

While under ventilation, her antibiotics were changed from Piperacillin/Tazobactam to renal adjusted dose of meropenem and levofloxacin. After change of antibiotics, her counts gradually decreased and became normal on the $5^{\text {th }}$ day of admission. Her serum creatinine on the $6^{\text {th }}$ and $7^{\text {th }}$ day was static at $1.7 \mathrm{mg} / \mathrm{dl}$ on both days. She was discharged on the 8th day after psychiatry consultation for deliberate self-harm. She was called for follow up after 7 days at medical outpatient department and her complete blood count, renal function tests and liver function tests had returned to normal.

\section{DISCUSSION}

Imidacloprid is classified as 'moderately toxic' (class II by World Health Organization and oral toxicity category II by U.S. Environmental Protection Agency). Imidacloprid is the most widely used neonicotinoids insecticide in agriculture for use on over 140 crops in more than 120 countries. $^{2}$ One of the reasons for its popularity and preference over organophosphorus compounds is its high potency against insects with low mammalian toxicity and favourable persistence. It is not banned or illegal to import in any country. It is designed to be effective by contact or ingestion. It is used to kill piercing and sucking pests, fleas, termites and also houseflies. ${ }^{3}$ The use of this insecticide for deliberate self harm has been increasing in other countries too. ${ }^{4}$

Imidacloprid acts through blockade of several types of post-synaptic nicotinic acetylcholine receptors (nAChRs), specifically $\alpha_{4} \beta_{2}$ subtype in pests. $^{5}$ However, nicotinoids formed as metabolites of neonicotinoids are more selective for vertebrate nAChRs than to insect nAChRs. ${ }^{6}$ Stimulation of nicotinic acetylcholine receptors in CNS leads to drowsiness, disorientation and coma while autonomic nervous system stimulation causes dilated pupils, sweating, tachycardia and arrhythmia. Individual variation in cytochrome $\mathrm{P}_{450}$ isoenzymes involved in imidacloprid metabolism 
is thought to contribute to variable toxicity in humans. ${ }^{7}$ Imidacloprid is ineffective on muscarinic receptors. ${ }^{5}$ Hence, there is no role of atropine in the management of Imidacloprid poisoning.

High dose of imidacloprid has been shown to cause significant elevation of ALT, AST, ALP and total bilirubin in mice. ${ }^{8}$ It has also been shown to cause damage to tubular epithelium in kidneys in chicken. ${ }^{3}$ The raised ALT, AST and creatinine in our patient resolved with supportive treatment. The other confounding factor in raised creatinine could be UTI which could have resolved with antibiotics, although the urine culture report showed no organism. Both CNS depression and respiratory failure seen in our patient have been described in case reports of Imidacloprid poisoning. ${ }^{4}$

Plasma concentrations of Imidacloprid as well as serum cholinesterase levels do not appear to be useful for guiding clinical management., 3 Features like dyspnea, apnea, mydriasis and coma indicate severe poisoning. Reports of death following ventricular fibrillation warrants ECG monitoring in these patients.

Due to absence of effective antidote, treatment of imidacloprid poisoning largely remains supportive. Respiratory arrest can be managed with ventilatory support. Gastric lavage can be performed in patients with recent ingestion. Oximes (e.g.pralidoxime) are either ineffective or contraindicated. ${ }^{9}$ In places where imidacloprid is available, imidacloprid toxicity should be considered in the differential diagnosis of multiorgan failure following unknown poisoning.

\section{CONCLUSION}

Although imidacloprid poisoning is not yet a common encounter in Nepal, it should be considered in the differential diagnosis of multiorgan involvement following unknown poisoning presenting to the Emergency Departments in Nepal.

\section{ACKNOWLEDGEMENTS}

ICU staff at Helping Hands Community Hospital, Chabhil.

\section{CONSENT}

Informed consent was was obtained from the patient for publication of this case report.

\section{CONFLICT OF INTEREST}

None declared.

\section{REFERENCES}

1. Proenca $\mathrm{P}$, Teixeira $\mathrm{H}$, Castanheira $\mathrm{F}$ et al. Two fatal intoxication cases with imidacloprid: LC/MS analysis, Forensic Sci. Int. 153 (2005) 75-80.

2. Elbert $A$, Haas $M$, Springer $B$ et al. Applied aspects of neonicotinoid uses in crop protection. Pest Manag Sci. 2008;64(11):1099-1105.

3. Kammon AM, Brar RS, Banga HS et al. Patho-biochemical studies on hepatotoxicity and nephrotoxicity on exposure to chlorpyrifos and imidacloprid in layer chickens. Veterinarski arhiv [Internet]. 2010 [cited 2021 April 14];80(5):663-672.

4. Mundhe S, Birajdar S, Chavan S et al. Imidacloprid poisoning: An emerging cause of potentially fatal poisoning. Indian Journal of Critical Care Medicine. 2017;21(11):786-788.

5. Buckingham SD, Lapied B, Corronc HL et al. Imidacloprid actions on insect neuronal acetylcholine receptors.JExp Biol. 1997;200(Pt 21):2685-92.

6. Tomizawa M, Casida J. Selective toxicity of neonicotinoids attributable to specificity of insect and mammalian nicotinic receptors. Annu Rev Entomol. 2003;48(1):339-364.

7. Schulz-Jander D, Casida J. Imidacloprid insecticide metabolism: human cytochrome P450 isozymes differ in selectivity for imidazolidine oxidation versus nitroimine reduction. Toxicollett. 2002;132(1):65-70.

8. Arfat $Y$, Mahmood $N$, Tahir $M$ et al. Effect of imidacloprid on hepatotoxicity and nephrotoxicity in male albino mice. Toxicol Rep. 2014;1:554-561.

9. Mohamed F, Gawarammana I, Robertson T et al. Acute Human Self-Poisoning with Imidacloprid Compound: A Neonicotinoid Insecticide. PLOS ONE. 2009;4(4):e5127. 